\title{
Modelling of Water Requirements for Some Vegetable Crops under Ismailia Conditions
}

\author{
Amr K. Mahmoud \\ Department of Physical and Soil Chemistry-Desert Research Center (DRC), Cairo, Egypt
}

\begin{abstract}
.
The scarcity of water resources around the globe has generated a need for their optimum utilization. Further; an agriculture consume a lot of water to irrigate crops, trees and landscape with different processes relying on climate data or soil data...etc. thus, dealing with this data help to maximizing on farm water management and rationalize unit of water. Using smart devices for irrigation management can help in achieving optimum water-resource utilization. This paper presents an open-source technology (Arduino Board) based smart algorithm, to predict the irrigation requirements using the sensing of ground parameter like Soil Moisture sensor, Real Time Clock (RTC) module, SD card module, Liquid Crystal Display. And, applied (Arduino design) at the field to irrigate a Bottle Gourd crop and comparing with CropWat model as a method for calculate the water requirement using climate data. Using Arduino device helps to rationalize a significant amount of water by $66.5 \mathrm{~mm}$ comparing with CropWat model. Furthermore, Arduino design with algorithm model gain a good value for (IWUE) by $\left(2.003 \mathrm{~kg} . \mathrm{m}^{-3}\right),(5.09$ ton. $\mathrm{fed}^{-1}$ ) for Yield production. In addition; this design helping for monitoring the changing in soil water content with reducing total water applied for Bottle Gourd crop.
\end{abstract}

Keywords: Arduino UNO, Bottle Gourd production, irrigation use efficiency, modeling, soil moisture, and water requirement.

DOI: $10.7176 / \mathrm{JNSR} / 11-20-04$

Publication date:October $31^{\text {st }} 2020$

\section{Introduction}

Water scarcity is already affecting a part of the world and the situation is getting worse over time due to the increasing world population and fresh water demands. The agriculture sector, particularly irrigation, consumes a major portion of the water. Therefore, there is a dire need to come up with advanced technologies based smart strategies and systems for effective utilization of water. Further, using smart agriculture technologies instead of traditional agriculture methods can able to get high production yield to manage the problems ( Mekala and Viswanathan, 2017).In the last decade, technological changes also affected agricultural crop production. With the help of sensor devices, farmers can remotely know about their field information like saturated soil temperature (Alahi et al., 2017), soil moisture (Markovic et al.,2015).

Noticeable, one of the new technologies which affect in agriculture is the Ardunio Uno or The Open-source microelectronics. This technologies have two main characteristics that have made these devices highly useful in different chemistry laboratories:(a) hardware costs are lower than traditional interfaces, and (b) the open-source software is free of charge (Grinias et al., 2016; Urban, 2014). Arduino has recently become a quite popular microcontroller (e.g. the most popular one is Arduino Uno). Arduino is an open electronic platform for the creation of prototypes based on both free software and low-cost hardware, the program is written in the $\mathrm{C}++$ code.

Soil moisture is a key variable in the climate system. By controlling evapotranspiration, soil moisture impacts the partitioning of incoming radiation into sensible and latent heat flux. In addition, Dry land and irrigated agriculture depend on the management of two basic natural resources; soil and water. Soil is the supporting structure of plant life and water is essential to sustain plant life. The wise use of these resources requires a basic understanding of soil and water as well as the crop itself. Further, Irrigating sandy soils requires high attention to the timing and amount of irrigation water applied (Sánchez. et al 2012), which are crucial decisions for each operator. Applying too much water means increased pumping costs, reduced water efficiency, and increased potential for pollutant leaching below the rooting zone and into the ground water. Delaying irrigation until plant stress is evident can result in economic yield loss.

Notable; that the Bottle gourd fruits are generally grown as a vegetable in Africa and Asia. Immature fruits are consumed by boiling, frying, or stuffing like the fruit of Cucurbita pepo. Shoots, tendrils, and leaves are also cooked, and the seeds are used for oil extraction or for cooking. The tendrils and young leaves are also utilized for some medicinal purposes (Tindall, 1983).Moreover; Bottle gourd has also been used routinely as a source of rootstock for watermelon and other cucurbit crops in some countries to reduce the incidence of soil-borne diseases and to develop the vigor of the root system of the crop under conditions of low temperature (Lee and Oda, 2003).

From the previous substantiation; The most useful measure of performance of an irrigation system, in terms of its effect on crop yield, is the water use efficiency (WUE) (Alghariani, 2002) which evaluates the proportion of the applied water beneficially used by the crops, WUE often defined by the ratio between the crop biomass or grain production and amount of water consumed by the crop, including rainfall, or the irrigation water applied, or 
the crop transpiration (zhang and oweis, 1999). and irrigation water productivity, the term WUE should be used as an indicator of the plants performance (Luis,S.Pereiar. et al 2002).

Thus, the aim of this work is design an open-source technology (Arduino Board) based smart algorithm, to predict the irrigation requirements using the sensing of ground parameter like Soil Moisture sensor. In addition; test this device for, reliability as a new technical for decide timing and amount of irrigation water applied, and applying on farm with cultivate a Bottle gourd as a vegetable crop.

\section{Material and Methods}

The experimental was carried out at farm faculty of agricultural - Suez Canal university - Ismailia governorate. The study site, established in late May of (2018), (30 $\left.37^{\prime} 10.91^{\prime \prime} \mathrm{N}-32^{\circ} 16^{\prime} 1.33 " \mathrm{E}\right)$. The site of experiment falls into an arid area with a Mediterranean climate. The site is about $30 \mathrm{~m}$ above sea level with an annual rainfall of $37 \mathrm{~mm} /$ year. The average climate characteristics for temperatures, relative humidity, wind speed and evapotranspiration (ETo) represented at (table 1).

Table 1: Climatic characteristics at Ismailia governorate.

\begin{tabular}{cccccccc}
\hline \multirow{2}{*}{ Month } & Prc. & Tem. max & Tem min. & Hum. & Sun shine & Wind $(2 \mathrm{~m})$ & ETo \\
\cline { 2 - 8 } & $\mathrm{mm} / \mathrm{m}$ & ${ }^{\circ} \mathrm{C}$ & ${ }^{\circ} \mathrm{C}$ & $\%$ & $\%$ & $\mathrm{~m} / \mathrm{s}$ & $\mathrm{mm} / \mathrm{d}$ \\
\hline may & 1 & 31.8 & 16.4 & 37 & 70 & 3 & 7.09 \\
\hline Jun & 0 & 34.8 & 19.5 & 39 & 77 & 3.2 & 8.03 \\
\hline Jul & 0 & 35.7 & 21.3 & 40 & 76 & 2.8 & 7.75 \\
\hline Aug & 0 & 35.3 & 21.5 & 43 & 77 & 2.5 & 7.04 \\
\hline Sep & 0 & 33.1 & 19.7 & 48 & 77 & 2.3 & 5.82 \\
\hline
\end{tabular}

$($ Prc. $=$ Precipitation; Tmp. $\min / \max =$ minimum/maximum temperature; hum. $=$ relative humidity; Sun shine $=$ Sun shine as percentage of day length; $\operatorname{Wind}(2 \mathrm{~m})=$ wind speed at $2 \mathrm{~m} ; E T o=$ Reference evapotranspiration)

Analyses of soil and some physicals were carried out according to Martin, (1993). These analyses are presented in (tables 2). The soil of the experimental site is sandy texture, none saline, and none calcareous. Silt and clay content are quite low there for both field capacity and available water are very low (8.2\% and $4.8 \%$ ).

Table 2.Particle size distribution for the experimental site.

\begin{tabular}{cccccc}
\hline Depth & \multicolumn{3}{c}{ Particle size distribution \% $(\mathrm{mm})$} & \multirow{2}{*}{ Textural class } \\
\cline { 2 - 5 } Cm & C.Sand & F.Sand & Silt & Clay & $\mathrm{S}^{*}$ \\
$0-20$ & 8.0 & 85.87 & 2.3 & 3.83 & $\mathrm{~S}^{*}$ \\
\hline
\end{tabular}

$\mathrm{S}^{*}=$ sand

Total water applied calculated related to the (Allen et al., 1998) FAO "Irrigation and Drainage Paper \#56: Crop Evapo-transpiration: Guidelines for Computing Crop Water Requirements using." Further; Crop water requirement and total water applied. Using an average Reference Evapo-transpiration (ETo) and the Crop coefficients (Kc) (Table 3 ) by the following Equations 1-3.

$$
\mathrm{ETc}=\mathrm{ETo} * \mathrm{KC}
$$

Where, ETc is the crop evapotranspiration and ETo is the reference evapo-transpiration (both measured in millimeters per day) and $\mathrm{KC}$ is the crop coefficient.

$$
\mathrm{IR}_{\mathrm{n}}=\mathrm{ETc}-\mathrm{P}_{\mathrm{eff}}
$$

Where, $I_{n}$ is the net irrigation requirement and ETc is the crop evapo-transpiration and $P_{\text {eff }}$ is the effective rainfall (all measured in millimeters per day).

$$
\mathrm{IR}_{\mathrm{t}}=\mathrm{IRn} / \mathrm{Ea}
$$

Where, $I_{t}$ is the total water applied, $I_{n}$ is the net irrigation requirement, (both measured in millimetres per day), and $E_{a}$ is the overall irrigation efficiency for a modern drip irrigation system (approximately (90\%) based on Vermeiren and Jobling (1984) and Phocaides (2007).

Table 3. The average crop coefficients $(\mathrm{Kc})$ for Bottle Gourd

\begin{tabular}{lccccc}
\hline \multicolumn{7}{c}{ Bottle Gourd } & Total. \\
\hline Item & Init. & Dev. & Mid. & Late. & 100 \\
\hline Days & 20 & 30 & 30 & 20 & \\
\hline KC & 0.6 & 1.0 & 1.0 & 0.8 & \\
\hline
\end{tabular}

The total water applied is $(738.8 \mathrm{~mm})$.

\section{Data acquisition system}

A data acquisition and control system was designed around an Arduino open-source microcontroller board to mange and model a water requFirement for Bottle Gourd production. The control system consists of hardware devices i.e. Arduino Board, Soil Moisture sensor, Real Time Clock (RTC) module, SD card module, Liquid Crystal Display ( LCD ) $16 \times 2$ character module and Breadboard Fig. 1 . The devices are implanted with programming to 
monitor the growth of the plant. The various components of the Electronic circuit are described as.

12C Backpack

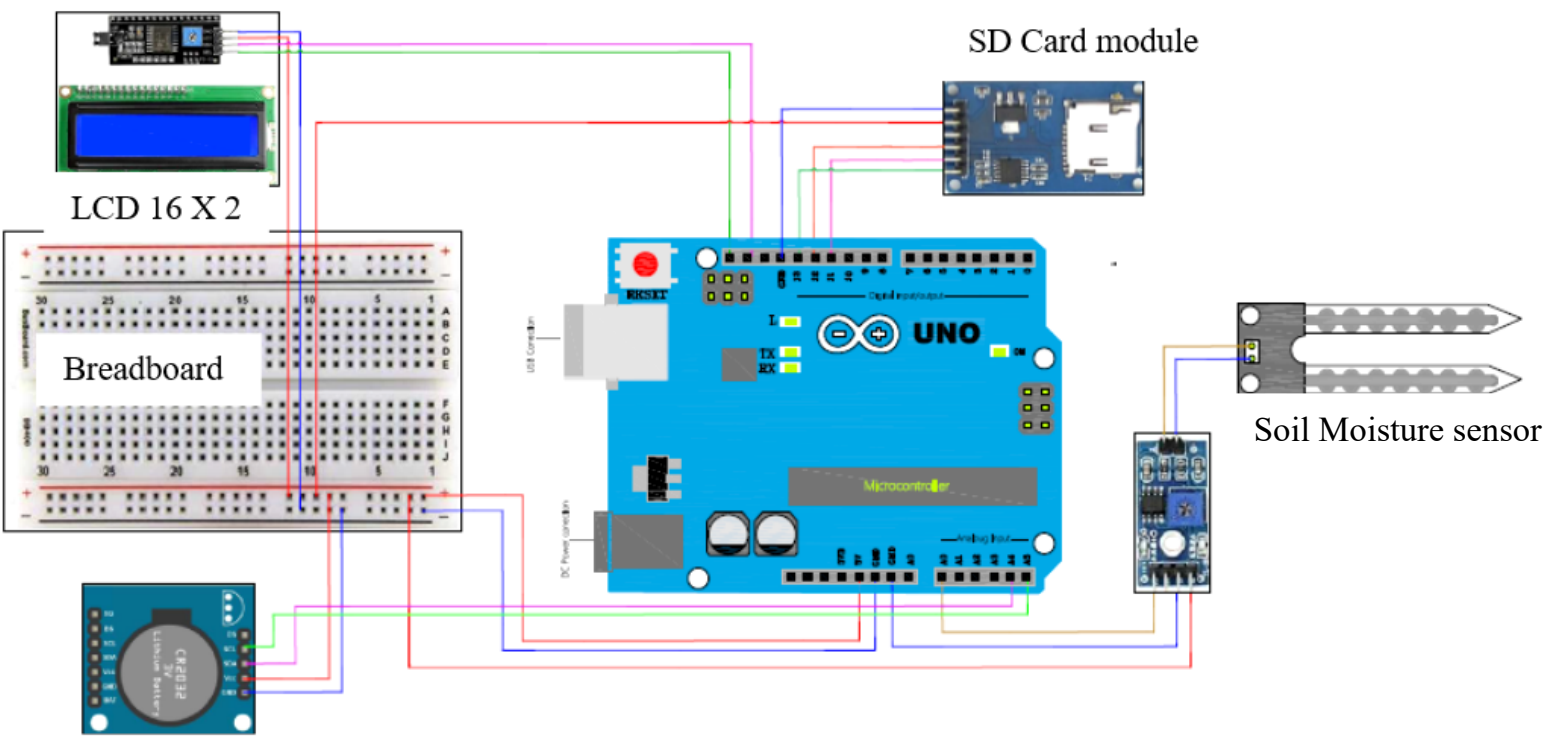

Real Time Clock

Fig. 1 Simplified wiring schematic for reading soil moisture for Bottle Gourd. With store the data and real time on SD card, and display the result, soil moisture real-time, on an LCD.

Arduino Uno Board is a Single board microcontroller hardware device used for connecting multiple sensors. It helps for sending and receiving data from source to destination. Arduino is classified into two parts i.e. hardware and software [11]. The Hardware part of Arduino Board is composed of many components that can help for transmitting and receiving data. Fig. 2 shows the Arduino board and its components. $\bullet$ USB socket (1): It is used for uploading program to the microcontroller and has a regulated power of $5 \mathrm{~V}$ which helps to provide power to Arduino board. $\bullet$ Reset Button (2): It is used to reset the currently uploaded command of Arduino. $\bullet$ Microcontroller (3): Arduino consists of ATmep3Z8 microcontroller that can help for sending and receiving information and provides commands to the circuits connected to it. $\bullet$ Voltage regulator (4): It helps in controlling the voltage supply in Arduino Board. - Barrel jack 5): It helps to provide power to the board and regulates voltage of 9-10 volts • Pins- Arduino board has 5V, 3.3V, GND, analog, digital pins. - Power pins(6,7)- 5V and 3.3V pins regulate the voltage of 5 volts and 3.3 volts respectively in board also known as power pins. - GND (8): GND refers to the ground which can be used to ground the design circuit. - Analog input (9): These pins are from A0-A5 helps in reading the analog data from the sensors. - Digital input/output (10): These pins are from 0 to 13 helps to provide digital information

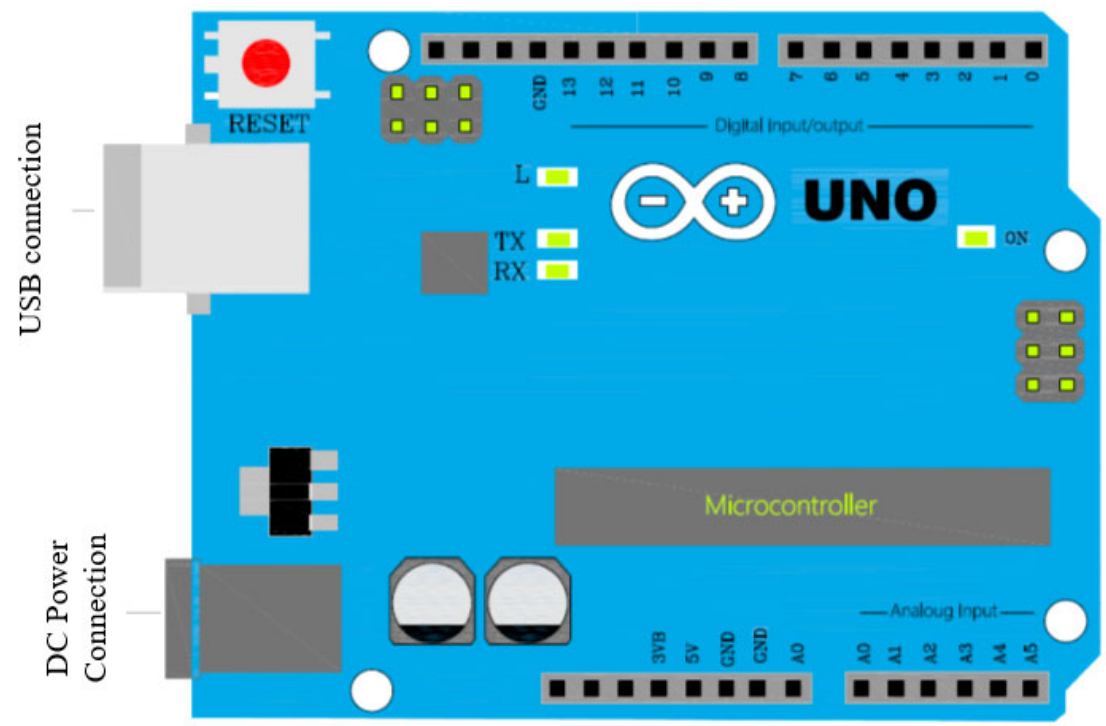

Fig. 2: Details for the Arduino Uno Board

Soil moisture sensor is determining the water content in the soil and works on the principal of electrical 
conductivity. Soil moisture sensor works on the property of the resistance, If the resistance of the soil between two point decreases than there is increase of water content in the soil. The soil moisture sensor LM293 comparator consists of two independent voltage comparators that are developed to operate from single power supply over a huge range of voltages Fig.3. The working of LM293 comparator lies between $-25^{\circ} \mathrm{C} \mathrm{to} 85^{\circ} \mathrm{C}$. The pins in the circuit are VCC, GND and A0. VCC pin helps in regulating the voltage into the circuit. GND is used to ground the circuit; A0 pin is used for analog data.

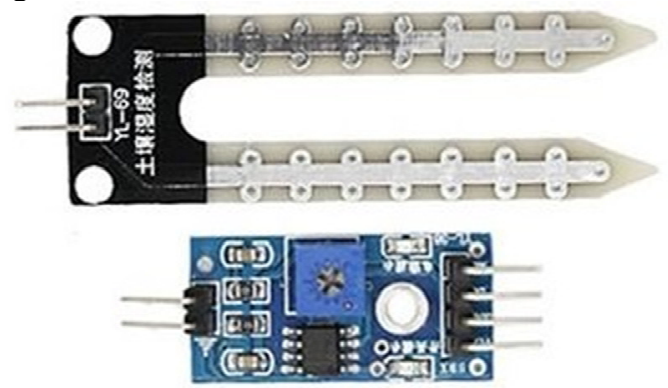

Fig. 3: Soil moisture sensor LM293

SD Card Module is used for transferring data to and from a standard SD card. In addition; is used to add mass storage and data logging to the project Fig.4. The pin out is directly compatible with Arduino. The pins in the circuit are VCC, GND, 12, 11 and 13. VCC pin helps in regulating the voltage into the circuit. GND is used to ground the circuit; 12,11 and 13 pin is used for digital data.

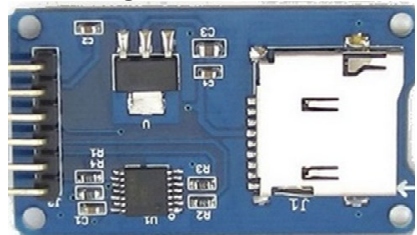

Fig. 4: SD card module

Real Time Clock Module (or DS1307) is a module that measures the time, and calendar i.e. hours, minutes, seconds as well as year, month and day, dependently or independently with Arduino card. An RTC is battery powered (CR2032-3V) and keeps track of the current time even when there is no power Fig. 5. The pins in the circuit are VCC, GND, A4 and A5. VCC pin helps in regulating the voltage into the circuit. GND is used to ground the circuit. A4 and A5 pin is used for analog data.

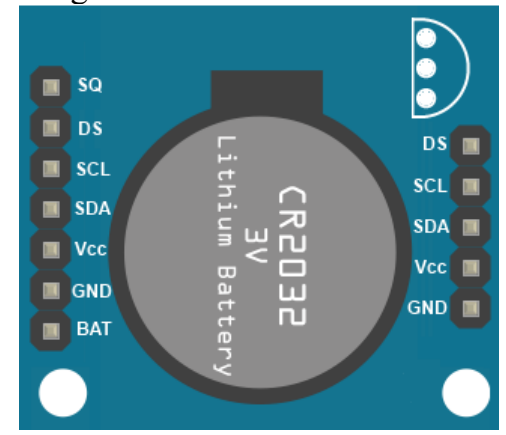

Fig. 5: Real Time Clock Module DS1307.

Liquid Crystal Display (LCD) with 12C Backpack $16 \times 2$ character modules there are 2 rows and 16 columns. Besides, $5 \times 8$ pixel makes a single digit. Moreover, there are two sections pins on the $16 \times 2$ LCD module. Some of them are data pins and some are command pin. Moreover; 12C Backpack uses PCF8574 Remote 8 bit I/O Expander fig. 6. It translates the data received from the I2C Bus into Parallel data that is needed for the LCD Display. The pins in the circuit are GND, VCC, SDA and SDL. GND is used to ground the circuit .VCC pin helps in regulating the voltage into the circuit. SDA is for data line and SDL is for clock line. 

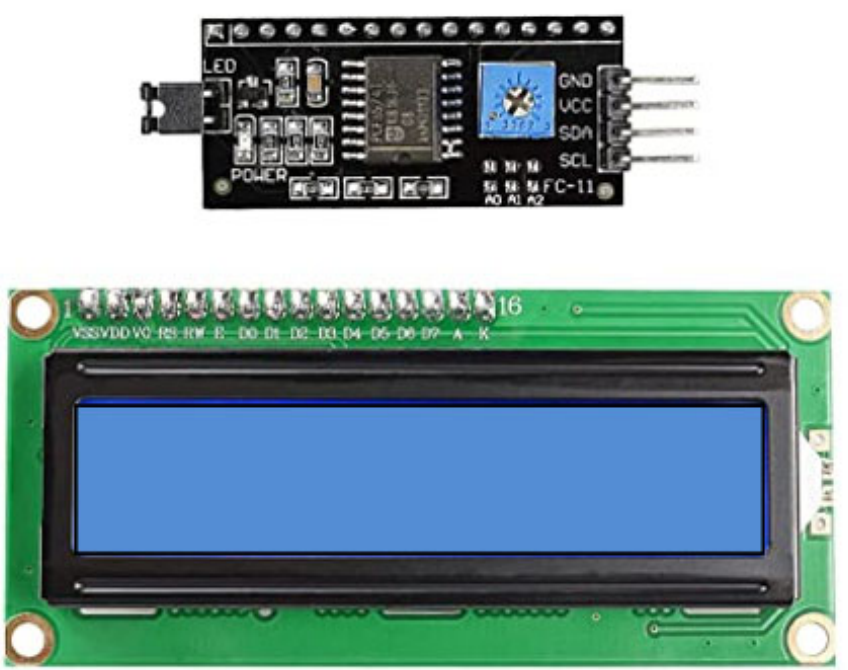

Fig. 6: Liquid Crystal Display (LCD) with 12C Backpack.

Breadboard is a rectangular plastic board with a bunch of tiny holes on it. These holes were helped easily insert electronic components to prototype of an electronic circuit. Finally, built the model or coding programme and upload it in Arduino board. This code is written by $\mathrm{C}++$ with an addition of special methods and functions; it is processed and compiled to machine language. Moreover; this code was built with the Arduino Integrated Development Environment (IDE) which the main text is editing program used for Arduino programming. Thus, the following algorithm (Fig. 7) is used to measure the soil moisture and water requirement value for crop a sequence of steps. In addition; first step at algorithm explains the connection between devises and sensors with an Arduino UNO board. Further, the remaining steps are related to reading data with printing on display and saving on memory card. The data acquisition is processed with a LM293 sensor (soil moisture). The algorithm shows information regarding soil moisture of the upcoming days. Also, provides irrigation suggestions, based on the defined level of soil moisture, to save water and energy. The generated information by algorithm and device is stored in SD card memory.

\section{Volumetric water content and calibration soil moisture sensor.}

Calibration the soil moisture sensor by Collect soil samples from the field and Air-dry the soil by spreading the soil samples. Remove stones, rocks, roots or other unwanted materials. After that the soil samples were divided on ten small plastic containers. Add a small amount of moisture started from second plastic container. In the third container, add a bit more moisture, and so on until the last container is full of saturated soil. Then measure the raw mille volt $(\mathrm{mV})$ from soil moisture sensor. Typically, the air-dried sample will have the lowest $\mathrm{mV}$ value and the saturated container will have the highest $\mathrm{mV}$ value. Finally, measure the actually soil water content using The measurement of water content is direct, being simply the mass of water $(M w, g)$ lost on drying in a convective oven at a specified temperature (usually $105^{\circ} \mathrm{C}$ ) until mass remains constant (usually $24 \mathrm{~h}$ ). Gardner (1986). The data are typically normalized by dividing by the sample dry mass. Direct water content measurements are called gravimetric measurements. Thus; the reported water contents are based on sample dry mass $\left(\mathrm{g} \mathrm{g}^{-1}\right)$ or on sample volume $\left(\mathrm{m}^{3} \mathrm{~m}^{-3}\right)$. The mass basis water content $\left(\theta \mathrm{m}, \mathrm{g} \mathrm{g}^{-1}\right)$ is

$$
\theta m=(\text { mass of water }) /(\text { mass of soil solids })=M w / M d
$$

Where, $M d$ is the mass of the soil after drying, and $M w=M s-M d$, where, Ms is the mass of the soil immediately after it is sampled (or before any water is lost). Then; the volumetric water content $\left(\theta v, \mathrm{~m}^{3} \mathrm{~m}^{-3}\right)$ can be calculated by converting the mass of water lost on drying to a volume equation (5).

$$
\theta v=(\text { volume of water }) /(\text { total soil volume })=(M w / \rho w) / V s
$$

Where, $\rho w$ is the density of water (typically assumed to be $\left.1 \mathrm{Mg} \mathrm{m}^{-3}\right)$. In addition; by knowing bulk density ( $\rho b$, $\mathrm{Mg} \mathrm{m}^{-3}$, which is the density of the soil including the pore space but excluding the mass of water, $\rho b=M d / V s$ ) of the soil can be estimated, then volumetric water content can be estimated from

$$
\theta v=(M w / \rho w) /(M d / \rho b)
$$






Fig. 7: The Algorithm Flowchart of the Proposed System.
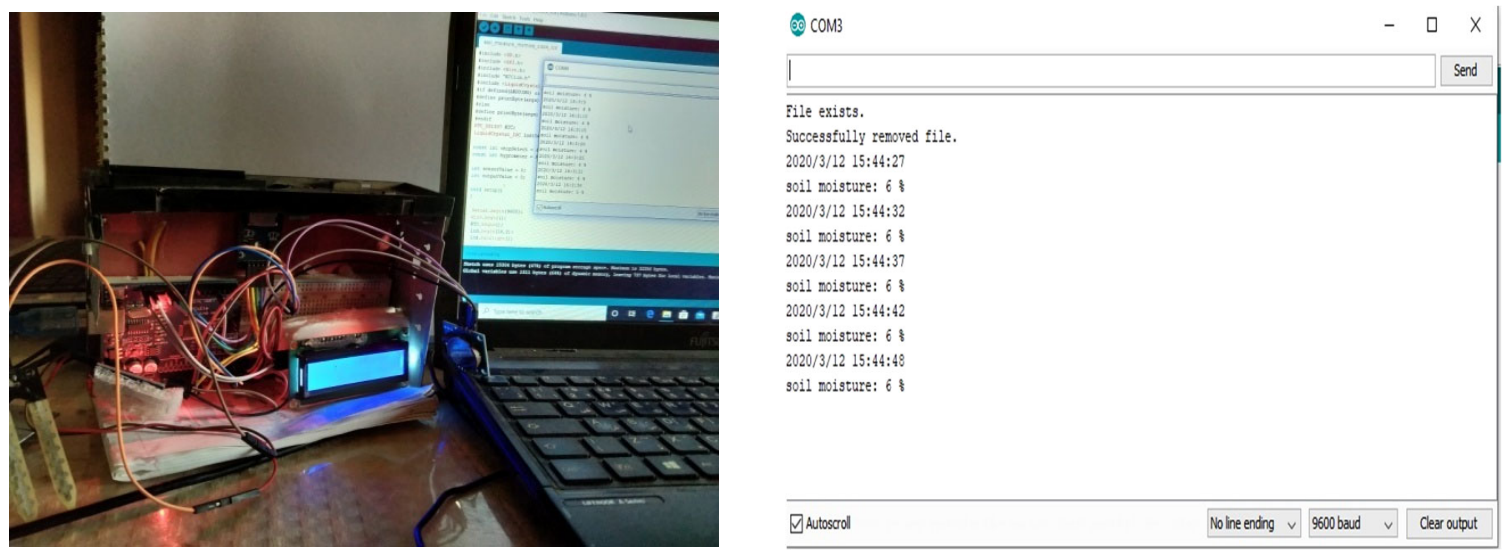

Fig. 8. Arduino UNO board measurement index experimental setup. 
The microcontroller board is appended with the LM293 sensor and Ethernet shield connected via a serial port of a laptop computer in which Arduino UNO is preinstalled. An appropriate algorithm is coded on the IDE and installed into the board. A user sitting at the local laptop machine or remote location can access the real-time information from the board and sends to the SD card. Fig. 8 shows the experimental design comprising a laptop, Arduino Uno and a LM293 placed over a breadboard connected with wires represents the IDE along with program running on Arduino UNO and the serial monitor output.

Irrigation water use efficiency using the Bos, M.G. (1979) equation (7).

$$
\mathrm{IWUE}=\left[\mathrm{Y}_{\mathrm{gi}}-\mathrm{Y}_{\mathrm{gd}}\right] / \mathrm{IRR}_{\mathrm{i}}
$$

Where, IWUE is Irrigation water use efficiency $\left(\mathrm{kg} / \mathrm{m}^{3}\right), Y_{\mathrm{gi}}$ is The economic yield $(\mathrm{kg} / \mathrm{fed}), \mathrm{Y}_{\mathrm{gd}}$ isThe dry yield (kg/fed) (Actually, the crop yield without Irrigation) Often, in most semiarid to arid locations, Ygd may be zero, and $\operatorname{IRR}_{\mathrm{i}}$ is the total irrigation water applied $\left(\mathrm{m}^{3} / \mathrm{fed}\right)$.

\section{Result and Discussion}

\section{Volumetric soil water content.}

As shown in fig. (9) The different between volumetric soil water content (VSWC) under the Cropwat model using climate data and irrigation using Arduino UNO board. The (fig 9. A) Reflect that cropwat irrigation start when (VSWC) recorded $\left(0.205 \mathrm{~m}^{3} \cdot \mathrm{m}^{-3}\right)$ at initial stage, and at development stage the irrigation accrued when (VSWC) obtained $\left(0.15 \mathrm{~m}^{3} \cdot \mathrm{m}^{-3}\right)$.in addition, at med stage and late stage the irrigation open at (VSWC) reached to ( 0.1 $\mathrm{m}^{3} \cdot \mathrm{m}^{-3}$ and $0.087 \mathrm{~m}^{3} \cdot \mathrm{m}^{-3}$ ) respectively. Thus; an average of total water applied recoded a $738.8 \mathrm{~mm}$ with drip irrigation system for Bottle Gourd crop. In contrast, at (fig. 9 B) irrigation using Arduino UNO board information, the irrigation start for initial and development stage when (VSWC) recorded $\left(0.22 \mathrm{~m}^{3} \cdot \mathrm{m}^{-3}\right)$ but at med and late season the action of irrigation accrued at (VSWA) reached to $\left(0.18\right.$ and $\left.0.19 \mathrm{~m}^{3} \cdot \mathrm{m}^{-3}\right)$.consequently; the value of total water applied obtained $672.3 \mathrm{~mm}$. On the other hand; using Arduino device helps to rationalize a significant amount of water by $66.5 \mathrm{~mm}$. Moreover, the designed system helps to give a data about an accurate amount of water which consumed by Bottle Gourd plant during a different stages. Thus; The designed system helps in reducing the usage of water because the irrigation did not start unless there is decrease in soil moisture (Divyansh et al.2018)
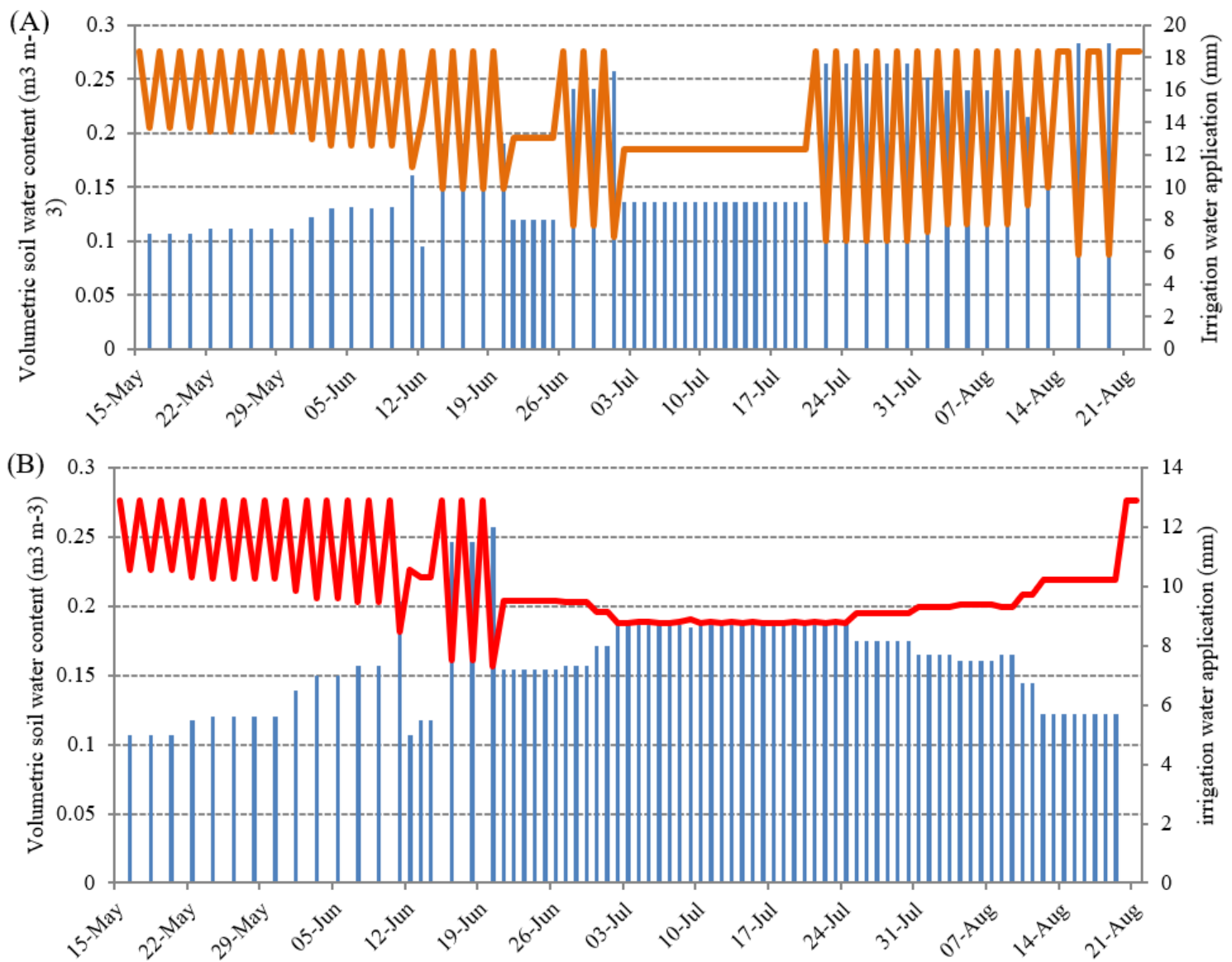

Fig. 9. The different between volumetric soil water content under the Cropwat model (A) using climate data and irrigation using Arduino Uno board (B). 


\section{Yield and Irrigation water use efficiency}

At (table 4) data indicated that there are significant impacts for different treatments (irrigation with Arduino device - Cropwat model using climate data) on yield of Bottle Gourd under. Furthermore; yield recorded (5.32 ton .fed

${ }^{1}$ ) which is a highest production under irrigation with climate data comparing with yield production under Arduino device which obtained (5.09 ton .fed $\left.{ }^{-1}\right)$. May this acquired because the amount of irrigation water under irrigation with Arduino device less than irrigation with climate data by $66.5 \mathrm{~mm}$. However; the irrigation water use efficiency (IWUE) recorded a highest value under irrigation with Arduino device by $\left(2.003 \mathrm{~kg} . \mathrm{m}^{-3}\right)$ however, the irrigation water use efficiency (IWUE) obtain $\left(1.904 \mathrm{~kg} . \mathrm{m}^{-3}\right)$ under irrigation using Cropwat model. Finally; from previous data analysis that the designee of Arduino board with algorithm model gain a good value for (IWUE), (Yield production) and helping to irrigation water management with reducing the total water applied for Bottle Gourd crop.

Table 4. Illustrate yield and irrigation water use efficiency for Bottle Gourd.

\begin{tabular}{|c|c|c|}
\hline \multirow{2}{*}{ ITEMS } & \multicolumn{2}{|c|}{ Treatments } \\
\hline & $\operatorname{Irr}_{\text {(Cropwat) }}$ & $\operatorname{Irr}$ (Arduino) \\
\hline Yield ( Ton.fed $\left.{ }^{-1}\right)$ & $5.32 \mathrm{a}$ & $5.09 \mathrm{~b}$ \\
\hline $\mathrm{LSD}_{0.05}$ & & \\
\hline IWUE $\left(\mathrm{kg} \cdot \mathrm{m}^{-3}\right)$ & 1.904 & 2.003 \\
\hline
\end{tabular}

\section{Conclusion}

The soil moisture is a critical parameter for developing a smart irrigation system. The soil moisture is affected by a number of environmental variables, e.g., air temperature, air humidity, UV, soil temperature, etc. With advancement technologies and smart devices by monitoring changes in the soil moisture the irrigation water management become easiest and effective. This paper proposes and designs a small device for monitoring changes in the soil moisture for decide the best irrigation time and amount for some vegetable crop (Bottle Gourd). The designed around an Arduino open-source microcontroller board to mange and model a water requirement for Bottle Gourd production. The control system consists of hardware devices i.e. Arduino Board, Soil Moisture sensor, Real Time Clock (RTC) module, SD card module, Liquid Crystal Display. Further; using this device to irrigate some crops as a (Bottle Gourd), and comparing with Cropwat model which uses a climate data to decide the irrigation time. Generally; using Arduino device helps to rationalize a significant amount of water by $66.5 \mathrm{~mm}$ comparing with other method. Finally, designee of Arduino board with algorithm model gain a good value for (IWUE), (Yield production) and helping to irrigation water management with reducing the total water applied for Bottle Gourd crop.

\section{Referance}

Alahi, M.E.E., L. Xie, S. Mukhopadhyay, L. Burkitt, 2017. A temperature compensated smart nitrate-sensor for agricultural industry, IEEE Trans. Industr. Electron. 64 (9) (2017) 7333-7341, https://doi.org/10.1109/TIE.2017.2696508.

Alghariani, S.A., 2002. Future perspectives of irrigation in southern Mediterranean region: policies and management issues. In: Al-Rasheed, M., Singh, V.P., Sheriff, M.M. (Eds.), Proceedings of the International Conference on Water Resources Management in Arid Regions 23-27 March, vol. 4, Kuwait, pp. 313-320.

Allen, R.G., Smith, M., Raes, D., Pereira, L. S., 1998. Crop evapotranspiration, guidelines for computing crop water requirements. FAO Irrigation and Drainage Paper No.56. Rome, Italy.

Bos, M.G. 1979. Standards for irrigation efficiencies of ICID. J. Irrig. Drain. Div. 105: 37-43.

Divyansh Thakur,Yugal Kumar, Arvind Kumar, Pradeep Kumar,Vijendra Singh.2018. Real Time Monitoring of Valeriana Jatamansi Plant for Growth Analysis. Procedia Computer Science 132 (2018) 507-517

Grinias, J.P., Whitfield, J.T., Guetschow, E.D., Kennedy, R.T., 2016. An inexpensive, open-source USB Arduino data acquisition device for chemical instrumentation. J. Chem. Educ. 93 (7), 1316-1319.

Martin. R.C., 1993.Soil Sampling and Methods of analysis.( $2^{\text {nd }}$ Edition) Lewis Puplishers, Washington D.C. USA, PP 499-569.

Mekala. M.S., P. Viswanathan, A novel technology for smart agriculture based on iot with cloud computing, 2017. International Conference on I-SMAC (IoT in Social, Mobile, Analytics and Cloud) (I-SMAC), 2017, pp. 7582, https://doi.org/ 10.1109/ I-SMAC.2017.8058280.

Phocaides, A. 2007. Handbook on Pressurized Irrigation Techniques, $2^{\text {nd }}$ Ed. Food and Agriculture Organization of the United Nations. Rome, Italy

Vermeiren, L. Jobling, G.A. 1984. Localized irrigation. FAO irrigation and drainage Paper No.36. FAO, Rome, Italy.

Gardner, W.H. 1986. Water Content. Chapter 21 in Methods of Soil Analysis, Part I, Physical and Mineralogical Methods. American Society of Agronomy and Soil Science Society of America, Madison, WI, USA.

Luis Santos Pereira, Theib Oweis and Abdel aziz Zairi., 2002. irrigation management under water scarcity. 
Agricultural water management 57 (2002) 175 - 206

Lee, J.M. and Oda, M., 2003. Grafting of herbaceous vegetable and ornamental crops. Horticultural Reviews, 28, 61-124.

Markovic , D., R. Koprivica, U. Pesovic, S. Ranic, 2015. Application of IoT in monitoring and controlling agricultural production, Acta Agric. Serbica 12 (40), (2015), 145-153.

Sánchez N., J. Martínez-Fernández, J. González-Piqueras, M.P. González-Dugo, G. Baroncini-Turrichia, E. Torres, A. Calera, C. Pérez-Gutiérrez, 2012 . Water balance at plot scale for soil moisture estimation using vegetation parameters. Agricultural and Forest Meteorology, Volumes 166-167, 2012, Pages 1-9.

Tindall HD, 1983. Vegetables in the Tropics. Macmillan Press, London

Zhang,H. and Oweis,T.,1999. water-yield relations and optimal irrigation scheduling of wheat in the Mediterranean region. Agric. water management .38,195-211

Urban, P.L., 2014. Open-source electronics as a technological aid in chemical education. J. Chem. Educ. 91 (5), $751-752$. 